\title{
Interpreting the Tests of Focal Cortical Dysplasia for Epilepsy Surgery Referral
}

\author{
Merrick S. Fallah, Binod Neupane, Mutaz Al Nassar, Rajesh RamachandranNair, \\ Kevin C. Jones
}

\begin{abstract}
Objective: Focal cortical dysplasia (FCD) is a common cause of refractory, focal onset epilepsy in children. Interictal, scalp electroencephalograph (EEG) markers have been associated with these pathologies and epilepsy surgery may be an option for some patients. We aim to study how scalp EEG and magnetic resonance imaging (MRI) markers of FCD affect referral of these patients for surgical evaluation. Methods: A single-center, retrospective review of children with focal onset epilepsy. Patients were included if they were between 1 month and 18 years of age, had focal onset seizures, prolonged scalp EEG monitoring, and an MRI conducted after 2 years of age. Statistics were carried out using the chi-squared and student's $t$-test, as well as a logistic regression model. Results: Sixtyeight patients were included in the study. Thirty-seven of these patients were referred to a comprehensive pediatric epilepsy program (CPEP) for surgical evaluation, and of these 22\% showed FCD EEG markers, 32\% FCD MRI markers, and 10\% had both. These markers were also present in patients not referred to a CPEP. The MRI markers were significantly associated with CPEP referral, whereas EEG markers were not. Neither marker type was associated with epilepsy surgery. Conclusion: This study found that children with focal onset epilepsy were more likely to be referred for surgical evaluation if they were medically refractory, or were diagnosed with FCD or tumor on MRI. Scalp EEG markers of FCD were not associated with CPEP referral. The online tool CASES may be a useful physician guide for identifying appropriate children for epilepsy surgery referral.
\end{abstract}

RÉSUMÉ: Interpréter les tests de détection de la dysplasie corticale focale en vue d'une évaluation préopératoire du traitement de l'épilepsie. Objectif : La dysplasie corticale focale (DCF) constitue une des causes communes des crises convulsives partielles réfractaires chez l'enfant. À la suite d'EEG effectués au niveau du cuir chevelu, des marqueurs de l'activité épileptique interictale ont été associés avec ce trouble pour lequel une intervention chirurgicale peut constituer, dans le cas de certains patients, une option. Nous voulons nous pencher sur la façon dont ces marqueurs et les marqueurs utilisés lors d'examens d'IRM pour la DCF peuvent affecter l'aiguillage de ces patients en vue d'une évaluation préopératoire. Méthodes : Dans un seul établissement hospitalier, nous avons effectué une analyse rétrospective de cas d'enfants chez qui sont apparues des crises convulsives partielles. Pour être inclus, les patients devaient être âgés de 1 mois à 18 ans, avoir été victimes de telles crises convulsives, avoir bénéficié de surveillance prolongée par EEG et avoir subi un examen d'IRM après l'âge de deux ans. Nous avons enfin effectué une analyse statistique à l'aide d'un modèle de régression logistique et des tests du $X^{2}$ et de Student. Résultats : Au total, nous avons inclus soixante-huit patients dans cette étude. Trente-sept d'entre eux ont été redirigés vers un programme pédiatrique complet de traitement de l'épilepsie (comprehensive pediatric epilepsy program) en vue d'une évaluation préopératoire. Sur ces trente-sept patients, on a observé chez $22 \%$ d'entre eux les marqueurs électroencéphalographiques associés à la DCF ; ce pourcentage atteignait $32 \%$ dans le cas des marqueurs de la DCF utilisés en imagerie ; enfin, on a pu détecter ces deux types de marqueurs chez $10 \%$ de ces trente-sept patients. Fait à souligner, ces marqueurs étaient aussi présents chez des patients n'ayant pas été orientés vers le type de programme cité ci-dessus. En outre, les marqueurs utilisés en imagerie se sont avérés étroitement associés au fait d'orienter des patients vers ce programme tandis que les marqueurs électroencéphalographiques ne l'étaient pas. Finalement, aucun de ces types de marqueurs n'a pu être associé à une intervention chirurgicale visant à traiter l'épilepsie. Conclusion : Cette étude a donc permis de constater que les enfants atteints de crises convulsives partielles étaient plus susceptibles d'être orientés en vue d'une évaluation préopératoire si leur trouble était de nature réfractaire ou s'ils avaient reçu un diagnostic de DCF ou de tumeur cancéreuse à la suite d'un examend'IRM. Les marqueurs électroencéphalographiques de la DCF n'ont pas été associés à un aiguillage vers un programme pédiatrique complet de traitement de l'épilepsie. Il se pourrait à cet égard que l'outil en ligne CASES soit un guide utile pour les médecins souhaitant identifier les enfants convenant à un aiguillage en vue d'un traitement chirurgical de l'épilepsie.

Keywords: Pediatric Focal Epilepsy, Scalp EEG, MRI, Epilepsy Surgery

doi:10.1017/cjn.2019.241

Can J Neurol Sci. 2019; 46: 559-565

Faculty of Medicine, University of Toronto, Toronto, Ontario, Canada (MSF); Faculty of Health Science, McMaster University, Hamilton, Ontario, Canada (BN, MAN, RR, KCJ); Department of Radiology, McMaster Children's Hospital, Hamilton, Ontario, Canada (MAN); Division of Pediatric Neurology, McMaster Children's Hospital, Hamilton, Ontario, Canada $(\mathrm{RR}, \mathrm{KCJ})$

Received August 21, 2018. Final Revisions Submitted June 28, 2019. Date of Acceptance July 2, 2019.

Correspondence to: Kevin C. Jones, Suite 3A50, 1280 Main Street West, Hamilton, Ontario L8S 4K1, Canada. Email: joneskc@mcmaster.ca 


\section{INTRODUCTION}

A child neurologist can effectively treat most children with epilepsy; however, about a third will have seizures that are treatment resistant after two tolerated, appropriate, anti-epileptic medications. ${ }^{1,2}$ These children, as well as those with focal onset epilepsy associated with an epileptogenic lesion on magnetic resonance imaging (MRI), are eligible for referral to a comprehensive pediatric epilepsy program (CPEP) for assessment of surgical candidacy. ${ }^{3}$ Epilepsy surgery has better outcomes than continued medical management alone. Limited awareness of surgical treatment options, however, leads to inappropriate patient referral and underutilization of epilepsy surgery in potential candidates.

Patients with lesions on MRI such as focal cortical dysplasia (FCD) are likely to be referred to epilepsy centers by neurologists; however, many FCD lesions go undetected on MRI when reported outside of a major epilepsy center. ${ }^{4}$ Bowen et al. also reported that out of an estimated 5170 children with drug refractory epilepsy in Ontario between 2011 and 2016, 2800 (54\%) received video electroencephalograph (EEG), while 2370 $(45 \%)$ were discussed at seizure conference. ${ }^{5}$

FCD is a common cause of medically refractory, focal onset epilepsy in children. It may comprise as much as $25-40 \%$ of refractory childhood epilepsies, with increasing incidence as imaging technologies improve. ${ }^{6}$ FCD is the most common cause of epilepsy surgery in children less than 4 years of age. ${ }^{7}$ The International League Against Epilepsy Sub-Commission for Pediatric Epilepsy Surgery identified FCD as one of the several etiologies and syndromes in children for epilepsy surgery evaluation. $^{3}$ It is a developmental, cortical migration disorder, classified by clinical-pathological criteria. ${ }^{8}$ These malformations are epileptogenic and can occur anywhere in the cortex, gray-white matter junction, or adjacent subcortical white matter.

FCD Type 1 has been associated with cerebral hypoplasia or mild blurring of the cortical-white matter junction on MRI. ${ }^{9}$ Tassi et al., however, reported MRI to be uninformative in 22/66 $(33 \%)$ cases of histologically confirmed FCD Type $1 .^{10}$ MRI features of FCD Type 2 include cortical thickening, blurring of the gray-white matter junction, gyration anomalies, subcortical white matter signal change, or the transmantle sign. ${ }^{9}$ Results vary according to the subtype of FCD with 23/34 (68\%) of FCD IIA and $61 / 66(93 \%)$ of FCD IIB, correctly diagnosed on MRI. ${ }^{11}$ Another study from the same group reported a normal MRI in 19/37 (49\%) of FCD IIA and 7 (9\%) of FCD IIB. ${ }^{12}$ A transmantle sign was significantly associated with FCD Type IIB. ${ }^{9,12,13}$ FCD Type III is a combination of abnormal cortical lamination with hippocampal sclerosis (Type IIIa), tumors (Type IIIb), vascular malformations (Type IIIc), or other acquired lesions (Type IIId). The dual pathology may be unappreciated on MRI, as the cortical lamination abnormality is often undetected. ${ }^{14}$

FCD has characteristic interictal EEG features. Rhythmic epileptiform discharges (REDs), rhythmic spikes or polyspikes, and repetitive bursts of fast waves (brushes) on scalp EEG correlate with continuous epileptogenic discharges (CEDs), rhythmic spikes or polyspikes and repetitive bursts of fast waves (brushes), observed during invasive monitoring using stereoelectroencephalograph (SEEG) or electrocorticography (ECoG), in patients with cortical dysplasia on histopathology. ${ }^{11,15-17}$ Gambardella reported REDs in 15/34 (44\%) and CEDs in
23/34 (67\%) patients with cortical dysplasia compared with REDs in $0 / 44(0 \%)$ and CEDs in $1 / 40$ (2.5\%) patients with non-dysplastic lesions. ${ }^{16}$

Brushes are significantly associated with the balloon cells of FCD IIB. ${ }^{11}$ Regional polyspikes on interictal scalp EEG were more often associated with FCD on MRI, than other regional interictal discharges. ${ }^{18}$

EEG biomarkers for FCD are specific but not very sensitive. The sensitivity of REDs to detect FCD compared to histopathology was $15 / 34(44 \%)$ with a specificity of $40 / 40(100 \%)$, and the sensitivity of regional polyspikes to detect FCD compared to MRI was $10 / 34(29 \%)$ with a specificity of $460 / 479(96 \%) .{ }^{16,18}$ The low sensitivity FCD findings on scalp EEG are probably explained by the well-known phenomenon of attenuation or distortion of cortical potentials by the tissues overlying the brain. ${ }^{16}$

Knowing the strengths and limitations of the tests of FCD is important when considering patients with focal onset epilepsy for surgical referral.

\section{OвJectives}

The goal of this study was to assess whether detection of FCD on MRI or prolonged interictal scalp EEG in children with focal onset epilepsy was associated with referral to a CPEP. Our hypothesis was that interictal focal polyspikes, fast waves, or REDs detected on prolonged scalp EEG and FCD on MRI are recognized by referring physicians as biomarkers of FCD, and that their detection is associated with referral to a CPEP for surgical evaluation. This study also aimed to identify other diagnostic predictors of referral to a CPEP.

\section{Methods}

We performed a single-center, retrospective health record review of children referred for prolonged scalp video-EEG monitoring at McMaster Children's Hospital. The pediatric neurologists who read and reported the EEGs participated in the study. The Hamilton Integrated Research Ethics Board approved the study (REB Application Number 2018-0860).

\section{Inclusion Criteria}

The study included children with focal onset epilepsy, between 1 month and 18 years of age, who completed a prolonged $(>1 \mathrm{~h})$ scalp EEG and had a brain MRI performed after 2 years of age at McMaster Children's Hospital between 2008 and 2015.

\section{Exclusion Criteria}

Children with generalized onset epilepsy or generalized epilepsy syndromes and with EEG diagnoses of electrographical status epilepticus in sleep, childhood epilepsy with central temporal spikes, multiple independent spike foci, Lennox-Gastaut Syndrome, nonepileptic seizures, or MRI diagnosis of tuberous sclerosis complex were excluded from the study. Children with Lennox-Gastaut Syndrome were excluded from the study, even though some of these patients have focal onset epilepsy, due to the presence of paroxysmal fast activity seen on EEG in this epilepsy syndrome.

Each patient's neurology clinic reports were reviewed for seizure and epilepsy types, epilepsy syndromes, etiology, CPEP referral, 


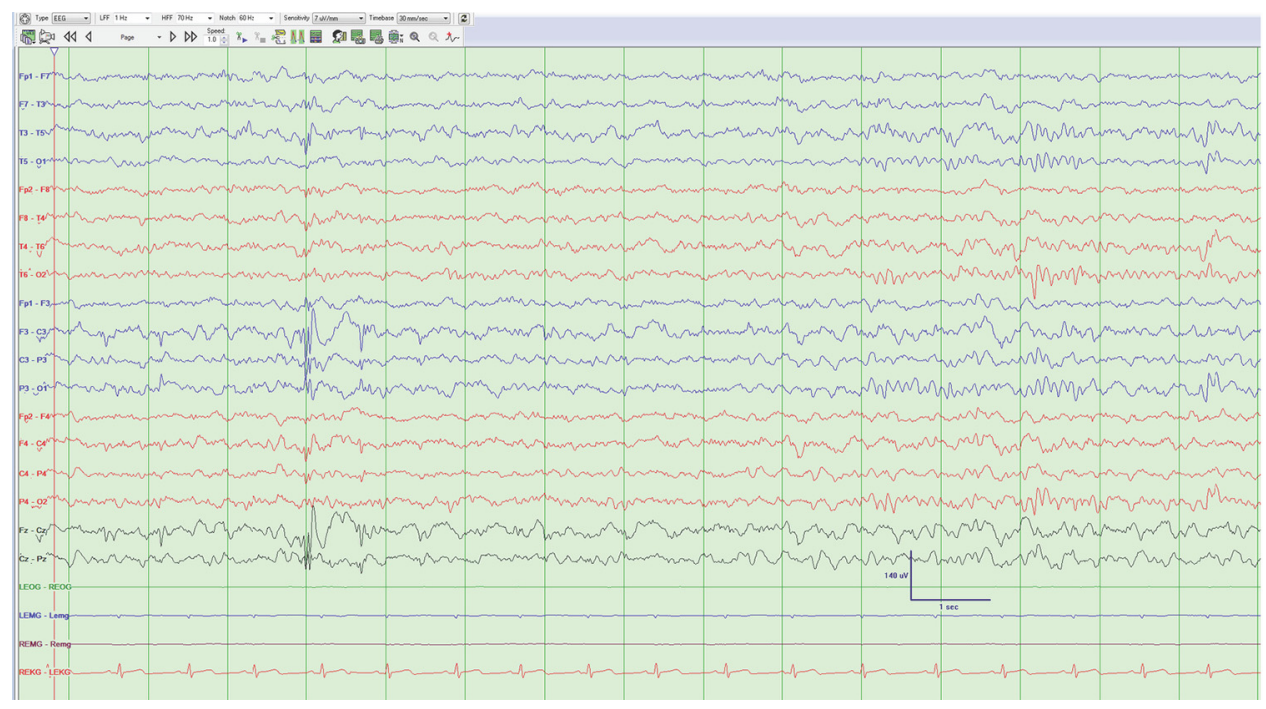

Figure 1: Left central and midline polyspike and wave complexes.

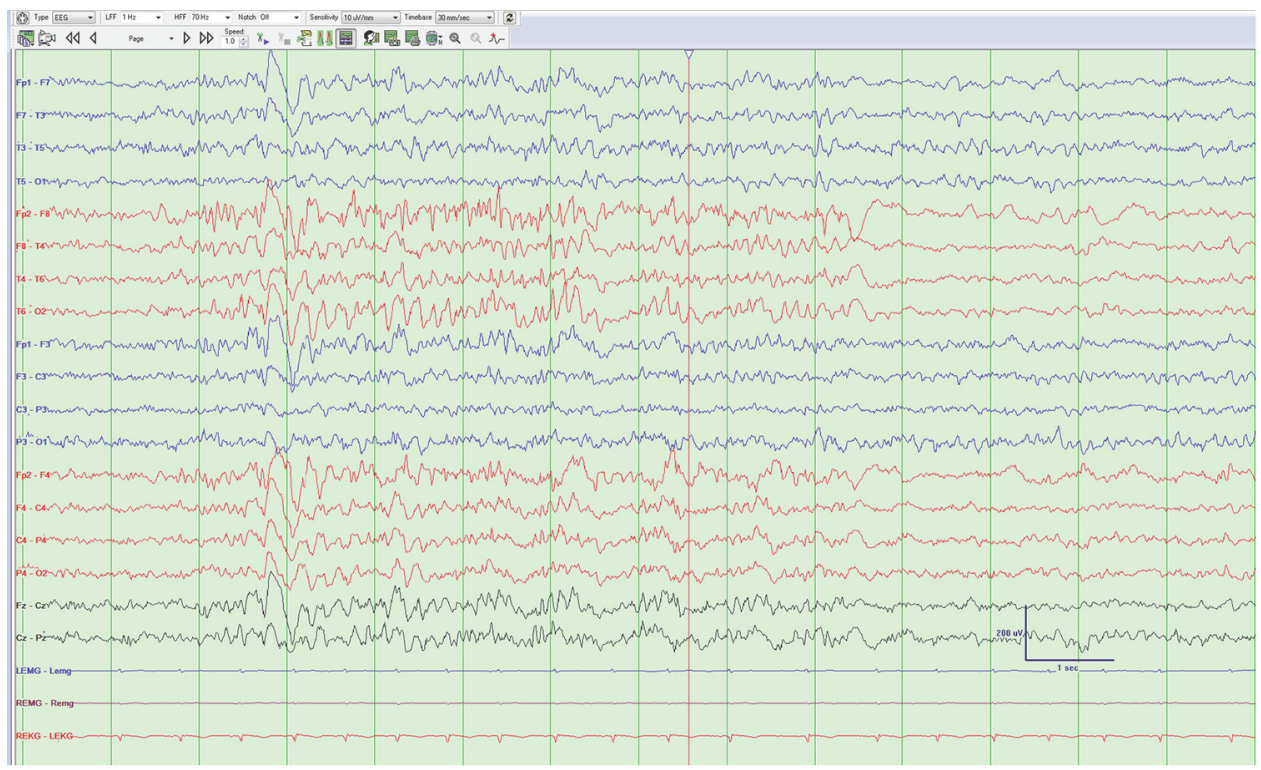

Figure 2: Bursts of fast waves from the right frontal region.

epilepsy surgery, and pathology. Prolonged $(>1$ h) scalp EEG reports were reviewed and categorized for interictal focal polyspikes, fast waves, or REDs. We elected to only assess the prolonged videoEEG studies, since the duration of recording has been shown to increase the yield of detecting interictal discharges. ${ }^{19}$

The MRI reports were reviewed for the presence or absence of FCD, malformations of cortical development other than FCD, tumor, stroke, vascular malformation, or mesial temporal sclerosis. All imaging sequences were obtained using a 1.5 Tesla (T) MRI.

\section{EEG Definitions}

Focal polyspikes (Figure 1): Interictal polyphasic spikes occurring at one or a few neighboring electrodes on EEG.

Focal fast waves (Figure 2): Interictal beta waves occurring at one or a few neighboring electrodes on EEG.
Rhythmic epileptiform discharges (Figure 3): Interictal stereotyped rhythmic sequences of repetitive sharp waves or spikes, lasting more than $1 \mathrm{~s}$ without clinical signs. ${ }^{16}$

\section{MRI Definitions}

Focal cortical dysplasia: Cortical thickening, blurring of the gray-white matter junction, gyration anomalies, subcortical white matter signal change, or a transmantle sign on MRI. ${ }^{9,12}$

\section{Outcome Measures}

The primary outcome measure was referral to a CPEP by a pediatric neurologist or pediatrician, and the secondary outcome was epilepsy surgery. The following variables were included in the analysis: sex, age of seizure onset, age at first prolonged scalp EEG 


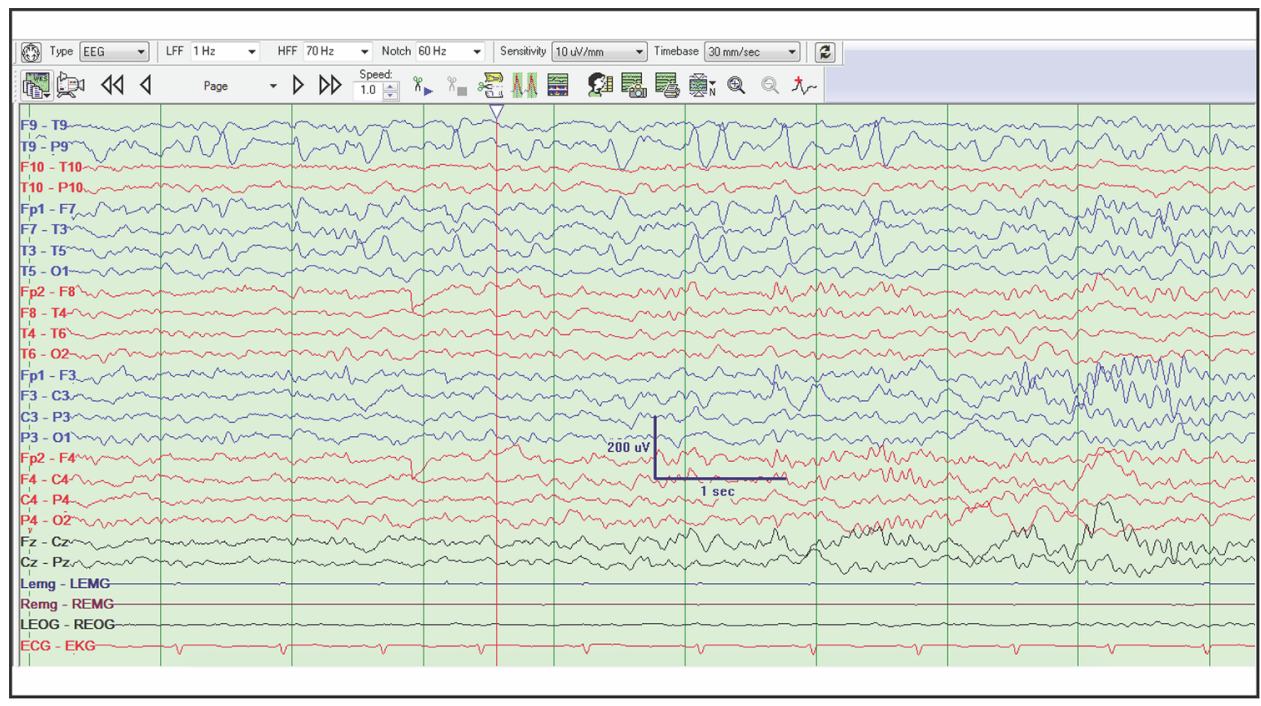

Figure 3: Rhythmic sharp waves from the left subtemporal and midtemporal regions without evolution.

and first MRI after 2 years of age, duration of prolonged scalp EEG, response to medication, signs of FCD on interictal scalp EEG, MRI diagnosis, and etiology. MRI diagnosis included FCD, malformations of cortical development other than FCD, tumor, stroke, vascular malformation, or mesial temporal sclerosis.

\section{Statistical Analysis}

Categorical and continuous variables were analyzed with $95 \%$ confidence intervals, using the chi-squared and student's $t$-test, respectively, with SPSS Statistics, Version 25. The variables were also analyzed using a logistic regression model.

\section{Results}

Two hundred and seventy children who completed a prolonged scalp video-EEG between 2008 and 2015 were evaluated for enrollment. Of these, 68 were included in the study.

Of the study cohort, there were $15 / 68$ (22\%) with FCD on interictal scalp EEG, 22/68 (32\%) with FCD on MRI, and 7/68 (10\%) with FCD on both. The MRI reports for EEG-onlypositive patients were not suggestive of FCD at any time on 1.5 T MRI, even though several patients had multiple MRI scans. For those with MRI evidence of FCD only, the interictal EEGs typically reported rare, intermittent, or frequent focal sharp waves, sharp and slow waves, or spike and waves. Focal delta or theta waves were also occasionally reported. When EEG findings of FCD were evident, they were reported in the body of the report. The report impressions focused on localization of the ictal onset and irritative zones. The EEG findings of FCD were correlated in the report with either a structural etiology or FCD in 6/15 cases.

Treatment resistant epilepsy was present in $12 / 15(80 \%)$ patients with EEG markers of FCD, 18/22 (81\%) with FCD on MRI, and $7 / 7(100 \%)$ of those with both markers. There was no difference in response to epilepsy treatment between those with the EEG marker and those with MRI findings of FCD. Differences in seizure frequencies between the groups were not recorded in the study, as this was not consistently reported in the medical charts.
Thirty-seven of the 68 (54\%) cases were referred to a CPEP. The referring physicians were pediatric neurologists or pediatricians. Of these, 9/37 (24\%) had signs of FCD on interictal scalp EEG, 19/37 (51\%) on MRI, and 6/37 (16\%) with FCD on both. For patients with both findings, they were discussed at seizure conference after the MRI was positive in five cases. One case was not referred.

All nine patients with FCD markers on EEG, referred for epilepsy surgery evaluation, had treatment-resistant epilepsy. Of the six patients with FCD markers on EEG not referred for epilepsy surgery evaluation, three had treatment-resistant epilepsy and the other three had treatment-responsive epilepsy.

Of the nine patients with FCD markers on EEG, referred for surgical evaluation, six included EEG findings of FCD or a structural etiology, in the impression of the EEG report, while in three, only the focal pattern of the EEG was discussed. Of the six patients with FCD markers of EEG, not referred for surgical evaluation, one included EEG findings of FCD or a structural etiology, while five only discussed the focal pattern of the EEG in the impression of the report.

The mean age of seizure onset was 84 months (SD 46 months) for the EEG-only patients, and 81 months (SD 49 months) for the MRI-only-positive patients $(p=0.88)$. These were not significantly different.

Thirty-one of the 68 cases (46\%) were not referred. Of the patients not referred for epilepsy surgery, 17/31 (54\%) had treatment-resistant epilepsy. There were 6/31 (19\%) with signs of FCD on interictal scalp EEG (3 had treatment-resistant epilepsy and 3 had treatment-responsive epilepsy), 3/31 (10\%) on MRI ( 1 with treatment-resistant epilepsy and 2 without), and 1/31 (3\%) with signs of FCD on both (with treatment-resistant epilepsy). Signs of FCD on MRI were significantly associated with referral to a CPEP $(p<0.05)$, while signs of FCD on EEG were not.

Seventeen of the $37(46 \%)$ referred to CPEP had epilepsy surgery. There were $3 / 17(18 \%)$ with FCD on interictal scalp EEG and $7 / 17$ (41\%) with FCD on MRI who had epilepsy surgery, compared with 6/20 (30\%) with FCD on interictal scalp EEG and 12/20 (60\%) with FCD on MRI who did not. Neither 
Table 1: Patient characteristics and referral predictors

\begin{tabular}{|c|c|c|c|c|c|c|c|}
\hline Variable & $\begin{array}{c}\text { Entire cohort } \\
\quad(N=68)\end{array}$ & $\begin{array}{l}\text { Surgical referral } \\
\qquad(N=37)\end{array}$ & $\begin{array}{c}\text { No referral } \\
(N=31)\end{array}$ & $p$ & Surgery $N=17$ & No surgery $N=\mathbf{2 0}$ & $p$ \\
\hline \multicolumn{8}{|c|}{ Sex, $N(\%)$} \\
\hline Female & $32(47)$ & $16(43)$ & $16(52)$ & 0.49 & $9(53)$ & $7(30)$ & 0.27 \\
\hline Male & $36(53)$ & $21(57)$ & $15(48)$ & & $8(47)$ & $17(70)$ & \multirow[b]{2}{*}{0.95} \\
\hline $\begin{array}{l}\text { Seizure onset } \\
\text { (months) Mean } \\
\text { (SD) }\end{array}$ & $77(53)$ & $78(49)$ & $77(59)$ & 0.97 & $78(50)$ & $77(50)$ & \\
\hline $\begin{array}{l}\text { Video-EEG age } \\
\text { (months) Mean } \\
\text { (SD) }\end{array}$ & $124(55)$ & $125(54)$ & $124(57)$ & 0.92 & $132(48)$ & $119(59)$ & 0.46 \\
\hline $\begin{array}{l}\text { Video-EEG duration } \\
\text { (h) Mean (SD) }\end{array}$ & $88(87)$ & $114(98)$ & $59(59)$ & 0.06 & $115(91)$ & $112(106)$ & 0.93 \\
\hline $\begin{array}{l}\text { MRI age (months) } \\
\text { Mean (SD) }\end{array}$ & $102(51)$ & $99(47)$ & $107(56)$ & 0.5 & $101(39)$ & $97(53)$ & 0.79 \\
\hline FCD on EEG, $N(\%)$ & $15(22)$ & $9(24)$ & $6(19)$ & 0.62 & $3(18)$ & $6(30)$ & 0.38 \\
\hline \multicolumn{8}{|c|}{ MRI diagnosis, $N(\%)$} \\
\hline FCD & $22(32)$ & $19(51)$ & $3(10)$ & 0.00 & $7(41)$ & $12(60)$ & 0.25 \\
\hline MCD & $3(4)$ & $2(5)$ & $1(3)$ & 0.66 & 0 & $2(10)$ & 0.18 \\
\hline Tumor & $8(12)$ & $7(19)$ & $1(3)$ & 0.04 & $5(29)$ & $2(10)$ & 0.13 \\
\hline Stroke & $6(9)$ & $1(3)$ & $5(16)$ & 0.05 & 0 & $1(5)$ & 0.35 \\
\hline AVM & $4(6)$ & $2(5)$ & $2(6)$ & 0.85 & $2(12)$ & 0 & 0.11 \\
\hline MTS & $2(3)$ & $1(3)$ & $1(3)$ & 0.9 & 0 & $1(5)$ & 0.35 \\
\hline \multicolumn{8}{|c|}{ Etiology, $N(\%)$} \\
\hline Structural & $35(33)$ & $23(62)$ & $12(39)$ & 0.54 & $10(59)$ & $13(65)$ & 0.7 \\
\hline Metabolic & $0(0)$ & 0 & 0 & - & 0 & 0 & - \\
\hline Genetic & $5(7)$ & $1(3)$ & $4(13)$ & 0.11 & $1(6)$ & 0 & 0.27 \\
\hline Immune & $2(3)$ & $1(3)$ & $1(3)$ & 0.89 & 0 & $1(5)$ & 0.35 \\
\hline Infectious & $2(3)$ & 0 & $2(6)$ & 0.11 & 0 & 0 & - \\
\hline Unknown & $24(35)$ & $13(35)$ & $14(45)$ & 0.4 & $6(35)$ & $7(35)$ & 0.98 \\
\hline $\begin{array}{l}\text { Medically } \\
\text { refractory, } N(\%)\end{array}$ & $52(76)$ & $35(94)$ & $17(55)$ & 0.00 & $17(100)$ & $18(90)$ & 0.18 \\
\hline
\end{tabular}

Children with focal onset epilepsy were tabulated according to epilepsy surgery referrals and nonreferrals, surgery vs. no surgery. The results were compared with respect to gender, age at seizure onset, age at first prolonged scalp EEG, EEG duration, FCD biomarkers on EEG and MRI, age at MRI, MRI diagnosis, etiology, and medication failure (AVM - arteriovenous malformation, MCD - malformations of cortical development, MTS - mesial temporal sclerosis, $N$ - number, SD - standard deviation). Bold values show $p$ values of $<0.05$.

signs of FCD on interictal EEG nor MRI were significantly associated with epilepsy surgery.

Of the six patients with FCD on both interictal scalp EEG and MRI referred for surgical evaluation, two underwent surgery. Pathology was reported as ganglioglioma in one patient and not available in the other. Of these patients who did not undergo surgery, one declined surgery, one was unable to tolerate intracranial monitoring, and two were not surgical candidates due to the inclusion of eloquent cortex within the epileptogenic zone. Of the eight patients with FCD on EEG only, three were referred for surgical evaluation and one had surgery, which was found to be a dysembryoplastic neuroepithelial tumor on pathology. One was not a surgical candidate and the other required further evaluation. Out of the 15 patients with FCD on MRI, only 10 were referred for surgical evaluation. Epilepsy surgery was undertaken in five, with one case of FCD, one of subcortical gray matter heterotopia, and two with ganglioglioma on pathology. Epilepsy surgery was not performed due to response to medication in four, eloquent cortex within the epileptogenic zone in one, inability to capture the ictal onset zone in one, and an unknown reason in another case. Of those with FCD neither detected on EEG nor on MRI, 15 were referred for surgical evaluation and 8 underwent surgery. Histopathology included hippocampal sclerosis (1), oligodendrogliosis (1), FCD IIA (1), gliosis (2), and nonspecific pathology (1).

The cohort was evaluated for predictors of referral to a CPEP. The results are tabulated in Table 1. Fifty-two of $68(76 \%)$ had medical refractory epilepsy. Of these, 35 out of 52 (67\%) were referred to a CPEP. Medically refractory epilepsy was significantly associated with referral to a CPEP $(p<0.05)$. 
There were $8 / 64(12 \%)$ cases diagnosed with tumor on MRI. Seven of eight (88\%) were referred to a CPEP, while $1 / 8(12 \%)$ was not. Tumor on MRI was significantly associated with referral to a CPEP $(p=0.04)$. There was no significant difference in referral to a CPEP or epilepsy surgery when sex, age of seizure onset, age at first prolonged scalp EEG, age at first MRI, duration of scalp EEG, etiology and MRI diagnosis of malformations of cortical development, stroke, vascular malformation, or mesial temporal sclerosis were evaluated.

Logistical regression analysis was performed. FCD on MRI was significantly associated with referral to a CPEP with an odds ratio of 7 (CI 2.04-24.06, $p<0.01$ ).

\section{Discussion}

This study found that children with focal onset epilepsy were more likely to be referred for surgical evaluation if they were medically refractory, or were diagnosed with FCD or tumor on MRI. Referring physicians are probably familiar with these indications for referral. Children with focal onset epilepsy and signs of FCD on prolonged scalp EEG, other structural lesions on MRI, or non-lesional medically refractory epilepsy were not more likely to be selected. This suggests that there is less awareness among physicians of the scalp EEG signs of FCD and the fact that FCD I, IIA, and III may be missed by MRI alone. A free online tool developed by the CASES expert panelists, using evidence and consensus opinions, is a useful guide for physicians in identifying children with focal epilepsy who may benefit from epilepsy surgery evaluation. ${ }^{20}$

Signs of FCD on interictal EEG or MRI were not significantly associated with epilepsy surgery. This suggests that other factors play a role in determining surgical candidacy. These include further investigations with high resolution, epilepsy protocolled MRI, fluorodeoxyglucose positron emission tomography, magnetoencephalography, ictal single-photon emission computed tomography, invasive monitoring with ECoG or SEEG, and high-frequency oscillation analysis, as well as neuropsychological testing and localization of eloquent cortex with functional MRI, and discussion at seizure conference in a CPEP. ${ }^{14}$ The potential epileptogenic zone may include eloquent cortex, which excludes epilepsy surgery as an option for some patients.

This study is limited by its retrospective, single-center design, relatively small sample size, use of $1.5 \mathrm{~T} \mathrm{MRI}$, and the number of subjects without MRI or EEG markers of FCD. The MRI and EEG data were collected from the patient's medical records without being reviewed objectively by the research physicians. The detection of FCD on MRI may therefore have varied between radiologists. The EEGs were originally read by one of the two study neurologists; however, the report impressions tended to emphasize the location of the interictal discharges rather than correlating clinically with a structural etiology or FCD. This may have limited the recognition of FCD and decision for referral by the primary neurologist. Referral paths also changed during the course of the study. The Hospital for Sick Children (Sickkids) in Toronto was the epilepsy surgery center for children in the Hamilton region between 2008 and May 2014. McMaster Children's Hospital was designated a District Epilepsy Centre in May 2014 with Sickkids as the Regional Epilepsy Centre. These changes may have affected the referral rates for children with FCD.
Knowing how to detect FCD, and the criteria for epilepsy surgery referral in children with focal onset epilepsy is essential to limit inappropriate referrals and underutilization of epilepsy surgery in potential candidates. The use of the free online tool developed by the CASES expert panelists is a useful adjunct for primary physicians caring for children with epilepsy.

\section{ACKNOWLedgements}

The authors thank the physicians, nurses and EEG technologists at McMaster Children's Hospital who cared for the patients presented in this study.

\section{CONFLICT OF INTEREST}

The authors have no conflicts of interest to disclose.

\section{Statement of Authorship}

MSF reviewed patient health records, collected data, identified patients for inclusion, interpreted the data, drafted the initial manuscript, reviewed, and revised the manuscript.

Dr. BN performed the statistical analysis, interpreted the data, reviewed, and revised the manuscript.

Dr. MAN reviewed and revised the manuscript.

Dr. RR reviewed and revised the manuscript.

Dr. KCJ reviewed the patient data and revised the manuscript.

\section{REFERENCES}

1. Kwan P, Brodie MJ. Early identification of refractory epilepsy. N Engl J Med. 2000;342:314-19.

2. Kwan P, Arzimanoglou A, Berg AT, et al. Definition of drug resistant epilepsy: consensus proposal by the ad hoc Task Force of the ILAE Commission on Therapeutic Strategies. Epilepsia. 2010;51:1069-77.

3. Cross JH, Jayakar P, Nordli D, et al. Proposed criteria for referral and evaluation of children for epilepsy surgery: recommendations of the Subcommission for Pediatric Epilepsy Surgery. Epilepsia. 2006;47:952-59.

4. Salamon N, Kung J, Shaw SJ, et al. FDG-PET/MRI coregistration improves detection of cortical dysplasia in patients with epilepsy. Neurology. 2008;71:1594-601.

5. Bowen JM, Snead OC, Chandra K, et al. Epilepsy care in Ontario: an economic analysis of increasing access to epilepsy surgery. Ont Health Technol Assess Ser. 2012;12:1-41.

6. Lee SK, Kim DW. Focal cortical dysplasia and epilepsy surgery. J Epilepsy Res. 2013;3:43-7.

7. Harvey AS, Cross JH, Shinnar S, et al. Defining the spectrum of international practice in pediatric epilepsy surgery patients. Epilepsia. 2008;49:146-55.

8. Blumcke I, Thom M, Aronica E, et al. The clinicopathologic spectrum of focal cortical dysplasias: a consensus classification proposed by an ad hoc Task Force of the ILAE Diagnostic Methods Commission. Epilepsia. 2011;52:158-74.

9. Colombo N, Salamon N, Raybaud C, et al. Imaging of malformations of cortical development. Epileptic Disord. 2009;11: 194-205.

10. Tassi L, Garbelli R, Colombo N, et al. Type I focal cortical dysplasia: surgical outcome is related to histopathology. Epileptic Disord. 2010;12:181-91.

11. Tassi L, Garbelli R, Colombo N, et al. Electroclinical, MRI and surgical outcomes in 100 epileptic patients with type II FCD. Epileptic Disord. 2012;14:257-66.

12. Colombo N, Tassi L, Deleo F, et al. Focal cortical dysplasia type IIa and IIb: MRI aspects in 118 cases proven by histopathology. Neuroradiology. 2012;54:1065-77. 
13. Barkovich AJ, Kuzniecky RI, Bollen AW, et al. Focal transmantle dysplasia: a specific malformation of cortical development. Neurology. 1997;49:1148-52.

14. Guerrini R, Duchowny M, Jayakar P, et al. Diagnostic methods and treatment options for focal cortical dysplasia. Epilepsia. 2015;56:1669-86.

15. Chassoux F, Devaux B, Landre E, et al. Stereoelectroencephalography in focal cortical dysplasia: a 3D approach to delineating the dysplastic cortex. Brain. 2000;123(Pt 8):1733-51.

16. Gambardella A, Palmini A, Andermann F, et al. Usefulness of focal rhythmic discharges on scalp EEG of patients with focal cortical dysplasia and intractable epilepsy. Electroencephalogr Clin Neurophysiol. 1996;98:243-49.
17. Palmini A, Gambardella A, Andermann F, et al. Intrinsic epileptogenicity of human dysplastic cortex as suggested by corticography and surgical results. Ann Neurol. 1995;37: 476-87.

18. Noachtar S, Bilgin O, Remi J, et al. Interictal regional polyspikes in noninvasive EEG suggest cortical dysplasia as etiology of focal epilepsies. Epilepsia. 2008;49:1011-17.

19. Narayanan JT, Labar DR, Schaul N. Latency to first spike in the EEG of epilepsy patients. Seizure. 2008;17:34-41.

20. Jette N, Quan H, Tellez-Zenteno JF, et al. Development of an online tool to determine appropriateness for an epilepsy surgery evaluation. Neurology. 2012;79:1084-93. 